\title{
A COOPERAÇÃO FEDERATIVA PARA A EFETIVAÇÃO DO DIREITO FUNDAMENTAL AO CLIMA ESTÁVEL
}

\author{
Carolina Mendonça de Siqueira ${ }^{1}$ \\ Sílvia Altaf da Rocha Lima Cedrola ${ }^{2}$ \\ Luiz Gustavo Gonçalves Ribeiro ${ }^{3}$
}

\section{RESUMO}

As mudanças climáticas reclamam novos paradigmas para compreensão do fenômeno e a busca de soluções para os problemas humanos e ecológicos. A necessidade de resguardar o equilíbrio climático, como pressuposto de proteção da dignidade humana, conduz ao reconhecimento do direito fundamental ao clima estável, protegido em âmbito internacional e pelo ordenamento jurídico brasileiro. $\mathrm{O}$ artigo aponta a importância da cooperação entre entes federativos para efetivação das medidas de mitigação e adaptação climática. A pesquisa é qualitativa, com caráter exploratório-explicativo, valendo-se das técnicas bibliográfica e documental. Foi empregado o método hipotético-dedutivo para o desenvolvimento do tema.

Palavras-chave: Cooperação; Direito Fundamental; Clima; Estabilidade; Mudanças Climáticas.

\section{THE FEDERATIVE COOPERATION FOR THE EFFECTIVENESS OF FUNDAMENTAL RIGHT TO STABLE CLIMATE}

\begin{abstract}
Climate change calls for new paradigms that allow the understanding of the phenomenon and the search for solutions to human and ecological problems. The need to safeguard climate balance, as a prerequisite for protecting human dignity, leads to the recognition of a fundamental right to a stable climate, protected both internationally and by the Brazilian legal system. The article points out the importance of cooperation between federative entities to implement climate mitigation and adaptation measures. The research is qualitative, with exploratory-explanatory character, using bibliographical and documentary techniques. The hypothetical-deductive method was used to develop a modest contribution on the subject.
\end{abstract}

Keywords: Cooperation; Fundamental Right; Climate; stability; Climate Changes.

\footnotetext{
${ }^{1}$ Pós-graduada em Direito Ambiental e Direito Urbanístico pela PUC Minas. Mestranda em Direito Ambiental e Desenvolvimento Sustentável na Escola Superior Dom Helder Câmara (ESDHC). Promotora de Justiça no Estado de Minas Gerais. Membro da Associação Brasileira dos Membros do Ministério Público do Meio Ambiente (ABRAMPA). End. Eletrônico: carolmsiqueira@yahoo.com.br. Tel. 31-99717-1274. Orcid. https://orcid.org/0000-0002-3173-5187

${ }^{2}$ Bacharel em Direito pela Universidade Federal de Juiz de Fora. Mestranda em Direito Ambiental e Desenvolvimento Sustentável na Escola Superior Dom Helder Câmara (ESDHC). Promotora de Justiça no Estado de Minas Gerais. End. Eletrônico: silviaaltaf@gmail.com. Orcid: http://orcid.org/0000-0002-6862$\frac{6427}{3}$

${ }^{3}$ Pós-doutor pela Università Degli Studi di Messina-IT. Doutor e Mestre pela UFMG. Professor do Programa de Pós-Graduação (mestrado e doutorado) em Direito Ambiental e Desenvolvimento Sustentável da Dom HelderEscola de Direito. Email: 1gribeirobh@gmail.com. Orcid: http://orcid.org/0000-0002-0065-1925
} 


\section{INTRODUÇÃO}

O século XXI, inevitavelmente, terá a marca dos desastres ambientais e das crises epidemiológicas globais, ambos determinados pela influência humana sobre o equilíbrio ecológico global. A característica universal das tragédias e dos riscos provoca a adoção de soluções cooperativas em âmbito internacional e subnacional. Ao mesmo tempo, a emergência climática antevista pela ciência ameaça o exercício dos direitos fundamentais à vida, à segurança, à liberdade e ao meio ambiente equilibrado.

Em vista disso, o artigo analisa os estudos produzidos pelo IPCC que revelam a decisiva contribuição humana para a elevação da temperatura global e recomendam a adoção de medidas de mitigação (redução das emissões de gases causadores do efeito estufa) e de medidas de adaptação (preparação e proteção contra as mudanças climáticas). Busca-se, ainda, um paradigma filosófico em Hans Jonas, cujo conceito do princípio responsabilidade ilustra a crise ecológica e ética dos tempos atuais.

A partir deste paradigma científico-filosófico, a análise se volta, ainda, para o reconhecimento de um direito fundamental ao clima estável que decorre dos acordos internacionais sobre o clima e da própria ordem constitucional brasileira após 1988. Há, porém, um problema quanto à efetivação deste direito em um país continental como Brasil, que possui diferentes climas, ecossistemas e vulnerabilidades socioeconômicas. O texto propõe, a partir do princípio federativo ecológico, o reconhecimento da cooperação em matéria climática, destacando o papel fundamental de Estados e Municípios na execução das políticas públicas climáticas.

A pesquisa é, deste modo, qualitativa, com caráter exploratório-explicativo, valendo-se das técnicas bibliográfica e documental, uma vez que foram levantados atos normativos, dados oficiais e estudos científicos sobre o fenômeno das mudanças climáticas, além da análise de obra filosófica de Hans Jonas e de doutrina sobre direitos fundamentais e princípios constitucionais. $\mathrm{O}$ emprego do método hipotético-dedutivo permitiu o desenvolvimento de contribuição quanto às obrigações dos entes subnacionais diante dos compromissos assumidos pelo Brasil no Acordo de Paris.

2 UM PARADIGMA FILOSÓFICO-CIENTÍFICO PARA A CRISE CLIMÁTICA 
As próximas décadas serão decisivas para a definição da situação climática global. Os meteorologistas afirmam que a intensidade dos fenômenos climáticos extremos aumentou e tende a se agravar em decorrência do aquecimento global (IPCC, 2021). A depender da graduação deste fenômeno, em um futuro próximo, os cidadãos globais poderão enfrentar prejuízos econômicos, sociais e ambientais, mais ou menos drásticos.

O reconhecimento da marca humana nas mudanças climáticas é contestado, na atualidade, por poucos. Majoritariamente, os cientistas afirmam que o aquecimento do planeta é inequívoco e sem precedentes (IPCC, 2014). Esta afirmação é um chamamento de ordem científica-filosófica, pois implica no reconhecimento de predições científicas com elevado grau de certeza e demanda uma redefinição filosófica e jurídica diante de um cenário de morte para ecossistemas e seres vivos.

No primeiro aspecto, a ciência permite compreender o fenômeno climático e seu agravamento, bem como prever, probabilisticamente, suas consequências. Em grande parte, a solução para o problema do aquecimento global também dependerá da adoção de alternativas tecnológicas que permitam a redução da contribuição humana.

As informações a respeito das mudanças climáticas advêm, principalmente, dos relatórios e estudos elaborados pelo IPCC, o Painel Intergovernamental sobre Mudanças Climáticas (na sigla em inglês - Intergovernmental Panel on Climate Change). Este órgão foi criado no âmbito do Programa das Nações Unidas para o Meio Ambiente (UNEP) e da Organização Meteorológica Mundial (WMO) em 1988. Composto por 195 membros de diferentes países, não exerce funções diretivas ou políticas, apenas estabelece, em seus relatórios, o estado do conhecimento sobre as mudanças climáticas. (IPCC, s.d)

Os principais relatórios do IPCC foram editados em 1990, 1995, 2001, 2007 e 2014. O sexto relatório deve ser concluído entre 2021-2022, já tendo sido publicizado um sumário inicial sobre as bases científicas elaboradas pelo primeiro grupo de trabalho. O último relatório completo (AR5 - Assessment Report) foi categórico ao afirmar que a influência humana sobre o clima é clara e que nunca houve um momento como o atual, no qual as emissões antropogênicas causadoras do efeito estufa estivessem tão altas (IPCC, 2014).

As emissões antropogênicas dizem respeito à liberação de gases como $\mathrm{CO} 2$ (dióxido de carbono), principal causador do fenômeno, além de CH4 (metano), N2O (óxido nitroso), entre outros gases e fatores relacionados a atividades humanas. O quinto relatório do 
IPCC enfatiza que as emissões decorrem do crescimento populacional, das atividades econômicas, do estilo de vida, do uso de energia e dos padrões de uso do solo. Se não houver mudanças substanciais que envolvam redução destas emissões, o aumento da temperatura implicará em impactos irreversíveis para as pessoas e os ecossistemas (IPCC, 2014).

A ocorrência de desastres climáticos, assim como outros de natureza ambiental, relaciona-se diretamente com a existência de vulnerabilidades antecedentes, de natureza social e econômica. De acordo com o Painel: "Climate change will amplify existing risks and create new risks for natural and human systems. Risks are unevenly distributed and are generally greater for disadvantaged people and communities in countries at all levels of development"4 (IPCC, 2014, p. 13). Assim, percebe-se que a situação de risco climático foi produzida e é vivenciada globalmente. No entanto, algumas comunidades sentirão de forma mais intensa os efeitos das mudanças climáticas, seja por sua localização geográfica, seja pela sua condição socioeconômica, que limita o acesso às medidas de proteção e tecnologias adequadas ao enfrentamento de desastres.

Contudo, a ciência não apenas expõe de forma antecipada as consequências das mudanças climáticas, estabelecendo a probabilidade causal da ocorrência de desastres, mas também oferece soluções que permitirão a prevenção ou, no mínimo, a suavização dos impactos. Decorrem do relatório de avaliação do IPCC os dois conceitos mais importantes para incorporação no estatuto jurídico dos Estados: mitigação e adaptação. Pelo primeiro, impõe-se aos Estados - compreendendo todos os atores sob sua jurisdição - a adoção de medidas e ações que efetivamente reduzam as emissões de gases causadores do efeito estufa. No cenário ideal, com a redução de emissões, o aumento da temperatura global seria limitado a $1,5^{\circ} \mathrm{C}$, não ultrapassando $2^{\circ} \mathrm{C}$, patamar máximo que acarretaria prejuízos e impactos extremos.

A adaptação, por sua vez, incide sobre os efeitos das mudanças climáticas, alguns dos quais inarredáveis, ainda que todas as medidas precautórias possíveis venham a ser adotadas pelos Estados. Trata-se de medidas que permitam reduzir os riscos e melhorar a resposta das comunidades e Estados aos impactos decorrentes das mudanças climáticas. Adaptação e mitigação devem estar integradas em todos os níveis de planejamento e ação estatal para a obtenção de resultados eficazes em face das mudanças climáticas.

\footnotetext{
${ }^{4}$ Tradução livre: "A mudança climática ampliará os riscos existentes e criará novos riscos para os sistemas naturais e humanos. Os riscos são distribuídos desigualmente e geralmente são maiores para pessoas e comunidades desfavorecidas nos países em todos os níveis de desenvolvimento"
} 
A concepção de mudanças climáticas, por si só, já conduz ao pensamento de que se trata de algo abstrato, pouco palpável e que foge ao controle humano, por se tratar de eventos da natureza, ainda que intensificados pela ação humana. Desde 2014, porém, os efeitos das mudanças climáticas têm sido observados com maior frequência, ao passo que os estudos da ciência da atribuição passaram a permitir uma melhor compreensão da relação de causa e efeito existente entre os eventos climáticos extremos e as emissões antropogênicas. No sumário apresentado em 2021 pelo IPCC, que constitui uma prévia do esperado Sexto Relatório, afirmam os cientistas que a temperatura global continuará a aumentar ao menos até meados deste século em todos os cenários analisados, sendo que, apenas se houver reduções significativas nas emissões de $\mathrm{CO} 2$ e outros gases do efeito estufa nas próximas décadas, será possível evitar que este aquecimento supere $1,5^{\circ} \mathrm{C}$ e $2^{\circ} \mathrm{C}$ (IPCC, 2021).

O que se propõe como paradigma científico pode ser definido como o grau de certeza do conhecimento sobre uma situação de crise climática em decorrência do fenômeno do aquecimento global, cujas causas residem em ações humanas e que exigem respostas adequadas e contundentes de todos os atores globais para seu enfrentamento.

O paradigma científico exige a adoção de uma nova postura ética, que fundamente a postura humana diante de um cenário de riscos extremos, causados pelo próprio homem e que pode representar a extinção de inúmeras espécies de seres vivos em razão de alterações ambientais significativas decorrentes das mudanças climáticas. Deve ser, inquestionavelmente, uma ética que reclame comprometimento e ação, como recomenda o paradigma científico, para a contraposição aos impactos previstos. Ao mesmo tempo, a catástrofe ambiental espelha as desigualdades socioeconômicas existentes no plano internacional e no interior das nações, atingindo de forma mais severa aqueles que se encontram em situação de vulnerabilidade.

Toma-se neste trabalho, como paradigma filosófico, o pensamento de Hans Jonas (1903-1993) e a teoria da responsabilidade. A obra publicada em 1979 pelo filósofo austríaco “O Princípio Responsabilidade: Ensaio de uma ética para a civilização tecnológica" se mantém atual para a análise do comportamento humano diante das ameaças provocadas pelo desenvolvimento da técnica moderna. Jonas refletirá sobre o desenvolvimento da técnica e suas repercussões sobre a vida e o próprio corpo do homem em decorrência do avanço da biologia molecular e da manipulação gênica com possíveis repercussões sobre a duração da vida e a moralidade dos experimentos com seres humanos futuros. 
Se a técnica pode interferir no agir humano, sendo, portanto, uma técnica diferente daquela conhecida em outros tempos, o filósofo reflete sobre a necessidade de um novo significado ético, que supere os pressupostos da ética tradicional. Com base nestas reflexões, Jonas propõe um imperativo ético construído sobre a responsabilidade, elevada a princípio fundamental que deverá guiar as ações do ser humano em relação aos males futuros.

Sim, lá onde aquela palavra não nos é fornecida gratuitamente, ou seja, pelo medo presente, torna-se um dever buscá-la, porque também ali não podemos dispensar a orientação do medo. Esse é o caso da "ética do futuro" que estamos buscando: o que deve ser temido ainda não foi experimentado e talvez não possua analogias na experiência do passado e do presente. (JONAS, 2006, p. 72)

O dever do qual Jonas fala no Princípio Responsabilidade não é construído com base na reciprocidade, como tradicionalmente se exigia dos direitos e deveres. Ao contrário, a reflexão do autor conduz à ideia de que aquilo que ainda não existe e, portanto, não pode reivindicar direitos, nem por isso pode ter seus direitos lesados. É, deste modo, uma ética para aquilo que não existe, o que torna o princípio da responsabilidade independente da reciprocidade (JONAS, 2006).

A ausência de reciprocidade revela um importante aspecto da nova ética apresentada que é sua projeção para a posteridade, ou seja, que o agir humano deve estar imbuído do dever de responsabilidade para com a humanidade futura, aqueles que ainda não existem e, portanto, não poderiam ter com relação aos presentes algum tipo de obrigação. É, precipuamente, para Jonas, uma responsabilidade que se relaciona com o direito de existir, pois, as ações humanas podem resultar na ausência do futuro ou da existência humana. $\mathrm{O}$ filósofo pode não ter cogitado, à época da elaboração de sua teoria, sobre a crise climática vivenciada no século XXI, cujas repercussões podem levar à extinção em massa de espécies em velocidade similar àquela de outras eras geológicas. Contudo, o direito ao futuro de espécies humanas e não humanas se apresenta de forma inexorável e reclama uma reflexão crítica sobre a conduta do homem em relação à natureza.

Jonas propõe o abandono das utopias em nome da responsabilidade, que é um convite ao agir (em substituição ao sonho). A manutenção do futuro, como revela o paradigma científico, depende de ações concretas e éticas adotadas por todos, ainda que as consequências do não-agir venham a ser sentidas de forma mais intensa pelos mais vulneráveis. Também neste ponto, a ética proposta por Jonas é profícua, uma vez que se preocupa com a situação dos mais fracos. 


\begin{abstract}
A esperança é uma condição de toda ação, pois ela supõe ser possível fazer algo e diz que vale a pena fazê-lo em uma determinada situação. [...] Com efeito, é uma das condições da ação responsável não se deixar deter por esse tipo de incerteza, assumindo-se, ao contrário, a responsabilidade pelo desconhecido, dado o caráter incerto da esperança; isso é o que chamamos de "coragem para assumir a responsabilidade".

O medo que faz parte da responsabilidade não é aquele que nos aconselha a não agir, mas aquele que nos convida a agir. (JONAS, 2006, p. 351)
\end{abstract}

Este é o paradigma filosófico proposto neste momento de incerteza e medo quanto ao futuro. A consciência da responsabilidade quanto ao futuro, a superação do medo paralisante por ações corajosas que conduzam ao melhor cenário previsto pela ciência. Essas ações exigem sacrifícios pela humanidade do presente em nome de uma geração futura, que ainda não existe, mas já tem direitos a reclamar. Deste modo, sob os alicerces da filosofia de Jonas, projeta-se a superação dos limites temporais para a compreensão dos deveres humanos com relação à preservação das condições climáticas e do meio ambiente para seres humanos e não-humanos.

\title{
3 O DIREITO FUNDAMENTAL AO CLIMA ESTÁVEL
}

Diante do paradigma filosófico-científico apontado para a compreensão das mudanças climáticas e da conduta humana em face do fenômeno, é necessário estabelecer o papel do Direito para a concretização da responsabilidade e a garantia da adoção de ações que sejam suficientes e temporâneas para proteção do equilíbrio climático para gerações presentes e futuras. A contraposição à crise climática requer ações em múltiplos níveis para conquista de um objetivo global. Em outro aspecto, a proteção à integridade climática pode ser inserida no espectro de defesa do direito meio ambiente equilibrado.

Em âmbito internacional, o reconhecimento do direito humano ao meio ambiente equilibrado foi consagrado na Declaração de Estocolmo (1972). Nas décadas seguintes, todos os tratados e convenções internacionais sobre o meio ambiente passariam a enfatizar a proteção ambiental como expressão do direito à vida e à dignidade da pessoa humana.

A Constituição Federal de 1988 elevou a temática, formal e materialmente, ao nível máximo do ordenamento jurídico brasileiro ao dispor no art. 225 que "Todos têm direito ao meio ambiente ecologicamente equilibrado, bem de uso comum do povo e essencial à sadia qualidade de vida, impondo-se ao Poder Público e à coletividade o dever de defendê-lo e preservá-lo para as presentes e futuras gerações” (BRASIL, 1988). O equilíbrio ambiental, em 
todos os seus múltiplos aspectos, constitui direito inalienável, imprescritível e irrenunciável do cidadão, ao qual foi atribuída a qualidade intertemporal, posto que pertence às gerações presentes e às futuras.

Refletindo sobre a atribuição de direitos às gerações futuras, Sarlet e Fensterseifer afirmam que, embora a admissibilidade desta hipótese seja ainda debatida na doutrina, existem, sem sombra de dúvidas, deveres fundamentais que limitam o exercício de outros direitos fundamentais pelas presentes gerações, sendo, portanto, vinculativos (SARLET; FENSTERSEIFER, 2019). A intergeracionalidade do direito fundamental ao meio ambiente equilibrado se adequa perfeitamente à característica da ubiquidade do bem jurídico ambiental. No momento presente, observa-se com maior frequência que os impactos ambientais não respeitam as fronteiras regionais ou internacionais, tampouco podem ser contidos em espaços de tempo.

No mencionado aspecto, as mudanças climáticas constituem um exemplo da dificuldade em se delimitar geograficamente e temporalmente os danos ambientais. Em primeiro lugar, porque a principal causa do problema advém de emissões antropogênicas oriundas de diversas partes do globo, efetuadas ao longo de décadas e que contribuíram de forma cumulativa para o fenômeno. Em segundo, os danos climáticos são, em regra, ultra fronteiriços, podendo ocorrer em pontos distantes das fontes de emissão. Ademais, como demonstram os estudos científicos, a continuidade dos padrões atuais de emissão representará riscos e impactos futuros. Vê-se, portanto, que existem relações bem estabelecidas entre as decisões tomadas pelas gerações passadas em relação às do presente e, ainda, entre as decisões do presente em relação à possibilidade das gerações futuras de usufruírem do direito ao meio ambiente equilibrado.

A proteção do clima está inserida no âmbito do direito ao meio ambiente equilibrado, mas pode ser compreendida também de forma autônoma, face à relevância do bem jurídico no contexto atual. Como destaca Christofoli, os riscos relacionados às mudanças climáticas vão além do âmbito de proteção do direito ao meio ambiente e exigem diferentes respostas estatais. $\mathrm{O}$ autor destaca a existência de um dever específico de proteção perante as mudanças climáticas que deve ser exercido através de medidas de mitigação e adaptação (CHRISTOFOLI, 2017).

A efetiva proteção de bens ambientais, como a água, o ar, as florestas, exige a adoção de medidas preventivas e reparatórias, que constituem aspectos da responsabilização 
ambiental decorrentes do dever constitucional. Já se percebe, contudo, que mesmo quanto a estes bens jurídicos há uma diversidade de medidas ajustadas aos casos concretos que ultrapassam o aspecto ambiental. Isso porque os riscos ou impactos ambientais interferem direta ou indiretamente sobre outros valores constitucionalmente protegidos como o patrimônio imaterial, a cultura, o direito à existência e à autopercepção de uma comunidade, o direito de ir e vir etc.

Deste modo, a situação de crise climática apenas confere relevo especial à necessidade de proteção da atmosfera e do clima global em face da magnitude dos danos decorrentes das mudanças climáticas. Além disso, além das medidas de mitigação - redução das emissões de gases de efeito estufa e aumento dos sumidouros de carbono, são necessárias medidas que não dizem respeito diretamente à prevenção ou à reparação de danos propriamente ditas, mas que envolvem a redução da vulnerabilidade das comunidades e indivíduos aos efeitos dos eventos climáticos extremos.

Deve-se, ainda, destacar que o desequilíbrio climático tem o condão de interferir no exercício de outros direitos fundamentais, seja de gerações presentes ou futuras, como o direito à liberdade e à vida digna, bem como à integridade ambiental, ameaçados pela possibilidade de extinção em massa de espécies e ecossistemas, pela elevação do nível dos oceanos, chuvas e secas intensas decorrentes das mudanças climáticas. Manifesta-se um verdadeiro direito fundamental ao clima estável, cuja existência possibilita a fruição de inúmeros direitos fundamentais, mas principalmente do direito à vida e à dignidade. Logo, a previsão do art. $1^{\circ}$ da Constituição Federal de 1988, ao estabelecer a dignidade da pessoa humana como fundamento do Estado Democrático de Direito, abrange, também, o novo imperativo do século XXI de proteção à integridade climática.

A configuração do direito fundamental ao clima estável na ordem jurídica constitucional brasileira vem sendo reconhecida por autores como Sarlet, Fensterseifer e Wedy. Durante a audiência pública da Arguição de Descumprimento de Preceito Fundamental (ADPF 708), que versa sobre a omissão estatal em relação ao Fundo Clima, Sarlet e Fensterseifer se manifestaram oralmente em defesa da dimensão ecológica da dignidade da pessoa humana, a qual se manifesta através de um mínimo de qualidade ambiental necessário à existência digna e a fruição de outros direitos.

Dito isso, entendemos possível também falar da configuração de um direito fundamental à integridade do sistema climático ou direito fundamental a um clima 
estável e seguro, como refere em sede doutrinária, o magistrado federal e professor Gabriel Wedy. De tal sorte, a integridade e estabilidade climática integra tanto o núcleo essencial do direito fundamental ao meio ambiente quanto o conteúdo do chamado mínimo existencial ecológico, podendo-se falar, inclusive, de um mínimo existencial climático, como indispensável a assegurar uma vida humana digna. (GEN JURÍDICO, 2020)

Wedy, a seu turno, demonstra a correlação entre o desenvolvimento sustentável e a dignidade da pessoa humana, já que não é possível conceber desenvolvimento econômico sem proteção ambiental, governança e inclusão social. Nesse sentido, defende que a insustentabilidade viola a dignidade, logo, o desafio atual seria a promoção do desenvolvimento sustentável em face das mudanças climáticas (WEDY, 2018).

Do reconhecimento da integridade ou estabilidade climática como um direito fundamental relacionado à dignidade da pessoa humana e ao direito ao desenvolvimento sustentável decorre o dever de proteção do Estado. Como já mencionado, este dever não implica somente em ações de defesa da atmosfera ou do clima, mas também em prestações positivas consistentes em planejamento, monitoramento, previsão de riscos e ações emergenciais, entre outras medidas de adaptação às mudanças climáticas. No ordenamento jurídico brasileiro, estas obrigações decorrem de acordos internacionais ratificados pelo Brasil e da legislação nacional que, conjuntamente, criam um arcabouço de normas para a concretização do direito fundamental ao clima estável.

\subsection{Os marcos jurídicos internacionais da proteção climática}

As questões relacionadas à proteção da atmosfera e do clima adquiriram maior proeminência em âmbito internacional durante Conferência das Nações Unidas para o Meio Ambiente e o Desenvolvimento, realizada no Rio de Janeiro em 1992, quando foi elaborada a Convenção-Quadro das Nações Unidas sobre Mudança do Clima (UNFCCC, da sigla em inglês United Nations Framework Convention on Climate Change). O documento foi ratificado pelo Brasil em 1994 e promulgado pelo Decreto n 2652/98. A Convenção expressa, em sua motivação, a preocupação com o aumento das emissões antropocêntricas e a necessidade de uma ação global cooperativa para proteção do sistema climático para gerações presentes e futuras 5 .

\footnotetext{
5 "Afirmando que as medidas para enfrentar a mudança do clima devem ser coordenadas, de forma integrada, com o desenvolvimento social e econômico, de maneira a evitar efeitos negativos neste último, levando
} 
A UNFCCC tem como um de seus princípios estruturantes o desenvolvimento sustentável, com especial atenção à situação dos países em desenvolvimento que precisam superar obstáculos econômicos e sociais e, ao mesmo tempo, necessitam de recursos e de tecnologia para reduzir emissões de gases do efeito estufa e obter maior eficiência energética. Ao seu lado, o espírito da convenção é informado pelo princípio das "responsabilidades comuns mas diferenciadas e respectivas capacidades e condições sociais e econômicas" (BRASIL, 1998). Como o extenso nome revela, as mudanças climáticas devem ser objeto de preocupação e ação efetiva por parte de todos os países, condição essencial para o sucesso do acordo internacional. No entanto, não podem ser desconsideradas as desigualdades existentes entre os diferentes Estados, que adotarão as medidas necessárias de acordo com suas capacidades (econômicas, sociais, tecnológicas), inobstante a cooperação entre todas as partes.

Passados cinco anos da UNFCCC, os Estados chegaram a um ajuste complementar, denominado Protocolo de Quioto ${ }^{6}$. No documento, foram estabelecidas obrigações específicas de redução de emissões pelos países desenvolvimento, não havendo previsão de metas semelhantes para os países em desenvolvimento. Todos os signatários reafirmaram o compromisso - segundo suas responsabilidades comuns mas diferenciadas - de formular programas nacionais e regionais de monitoramento do volume de emissões e remoções, bem como a adoção de medidas de mitigação e adaptação às mudanças climáticas (art. 10).

Finalmente, em 2015, um novo acordo complementar à Convenção-Quadro foi elaborado, o Acordo de Paris. Neste documento, concebido durante uma situação de emergência climática, segundo as predições do $5^{\circ}$ relatório do IPCC, todos os Estados signatários se comprometeram a medidas e políticas efetivas que conduzam ao objetivo de neutralidade climática até a metade do século. Para que se possa chegar em 2050 com zero emissões líquidas de carbono, o Acordo de Paris toma como princípios informadores a

plenamente em conta as legítimas necessidades prioritárias dos países em desenvolvimento para alcançar um crescimento econômico sustentável e erradicar a pobreza, (...) Determinadas a proteger o sistema climático para gerações presentes e futuras" (BRASIL, 1998, s.p)

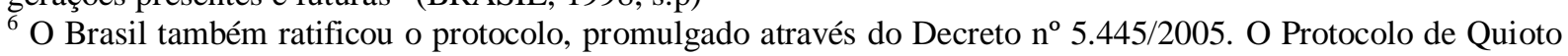
somente entrou em vigor em fevereiro de 2004, em razão da previsão no corpo do texto de que houvesse a ratificação de países que representassem ao menos $55 \%$ das emissões de gases de efeito estufa mundiais para sua vigência. 
progressividade das contribuições nacionais ${ }^{7}$ e a maior ambição possível, de acordo com as responsabilidades comuns mas diferenciadas (art. $4^{\circ}$ ). Isso significa que países desenvolvidos e países em desenvolvimento devem produzir esforços no sentido de reduzir suas fontes de emissões, conservar e fortalecer sumidouros e reservas de carbono (como os ecossistemas florestais).

O Brasil ratificou o Acordo de Paris (Decreto $n^{\circ}$ 9.073/2017) e apresentou junto à Organização das Nações Unidas sua contribuição nacionalmente determinada (NDC, sigla da expressão nationally determined contribution). De acordo com as obrigações internacionais, o país deve adotar medidas de mitigação para que sejam alcançados os objetivos previstos na NDC. Estas medidas devem se traduzir em políticas e planos nacionais e regionais que demonstrem o progresso na realização da meta de mitigação e que ampliem a capacidade de resiliência de seus ecossistemas e comunidades vulneráveis.

Há uma grande ênfase no Acordo de Paris na adoção de medidas de adaptação, que decorrem do fato de que, à mingua dos esforços adotados até então em âmbito global, alguns impactos decorrentes do aquecimento global serão inevitáveis. Como consequência, é imprescindível que os Estados-parte, como o Brasil, preparem-se para cenários de alterações climáticas que afetarão atividades produtivas e sistemas sociais. Outrossim, num país continental como o Brasil, com ecossistemas e climas regionais diversos, amplia-se a necessidade de atuação coordenada e descentralizada de planejamento e ação.

Nesse sentido, deve ser analisada a Política Nacional de Mudanças Climáticas e as prescrições nela contidas que ensejam a efetivação do direito fundamental ao clima estável mediante políticas de todos os entes e órgãos públicos federativos.

\subsection{A política climática brasileira}

Além dos acordos internacionais ratificados pelo Brasil e, deste modo, incorporados ao ordenamento jurídico brasileiro, foi editada a Lei ${ }^{\circ} 12.187 / 2009$, que instituiu a política nacional sobre mudança climática - PNMC. A legislação tem como objetivos a compatibilização do desenvolvimento sustentável - um dos princípios por ela adotados - com a proteção do sistema climático, a promoção da redução das emissões

\footnotetext{
${ }^{7}$ As contribuições nacionalmente determinadas são documentos que devem ser elaborados pelas partes do Acordo de Paris e apresentados à Conferência das Partes, devendo conter os objetivos de mitigação e as medidas a serem adotadas para que estes sejam atingidos. (artigo $4^{\circ}$, Decreto $n^{\circ} 9073 / 217$ )
} 
antrópicas de gases do efeito estufa e de medidas de adaptação pelas três esferas da federação, entre outros. Deste modo, os objetivos e diretrizes da PNMC se encontram ajustados às obrigações assumidas perante o Acordo de Paris em 2015.

O reconhecimento do direito fundamental ao clima estável pode ser identificado nas prescrições da política nacional sobre a responsabilidade dos entes e órgãos públicos na execução das ações previstas na lei. A PNMC tem como fundamento expresso o dever de atuação estatal para a redução dos impactos humanos sobre o sistema climático em benefício das gerações presentes e futuras (artigo $3^{\circ}$, I, Lei 12.187/2009). Para se atingir este objetivo, a lei preconiza a integração das ações em âmbito nacional, estadual e municipal, além da colaboração de outras entidades e agentes econômicos e sociais.

Entre as diretrizes estabelecidas pela política nacional, destaca-se:

\footnotetext{
Art. $5^{\circ}$ São diretrizes da Política Nacional sobre Mudança do Clima:

I - os compromissos assumidos pelo Brasil na Convenção-Quadro das Nações Unidas sobre Mudança do Clima, no Protocolo de Quioto e nos demais documentos sobre mudança do clima dos quais vier a ser signatário;

II - as ações de mitigação da mudança do clima em consonância com o desenvolvimento sustentável, que sejam, sempre que possível, mensuráveis para sua adequada quantificação e verificação a posteriori;

III - as medidas de adaptação para reduzir os efeitos adversos da mudança do clima e a vulnerabilidade dos sistemas ambiental, social e econômico;

IV - as estratégias integradas de mitigação e adaptação à mudança do clima nos âmbitos local, regional e nacional;

V - o estímulo e o apoio à participação dos governos federal, estadual, distrital e municipal, assim como do setor produtivo, do meio acadêmico e da sociedade civil organizada, no desenvolvimento e na execução de políticas, planos, programas e ações relacionados à mudança do clima; (BRASIL, 2009)
}

É inequívoca a importância da integração das prescrições da política nacional de mudanças climáticas nos programas de atuação de todas as esferas de governo, da Administração Direta e Indireta, uma vez que as medidas de mitigação das emissões e preservação dos sumidouros e reservas de carbono precisam ser difundidas nacionalmente e incorporadas em todos os setores econômicos, especialmente, de energia, indústria, transporte e de proteção ambiental. No mesmo sentido, as ações de adaptação somente serão efetivas se identificadas as vulnerabilidades regionais e locais, de modo que se possam traçar estratégias diferentes segundo as particularidades de cada comunidade ou ecossistema. Tome-se como exemplo, a extensa costa litorânea brasileira, que poderá sofrer impactos decorrentes da elevação do nível dos oceanos, assim como o aumento da vulnerabilidade em regiões urbanas em razão de eventos climáticos extremos como chuvas intensas e enchentes. 
As alterações climáticas já são percebidas com maior intensidade nos últimos anos, tendo causado prejuízos econômicos e financeiros, além de perdas humanas em diversos países $^{8}$. A ausência de preparo das autoridades locais e regionais para lidar com os eventos climáticos extremos demonstra a necessidade de descentralização da política nacional climática, como prescreve a Lei $n^{\circ} 12.187 / 2009$. Mais de dez anos após a entrada em vigor da legislação, muitos Estados brasileiros não possuem planos de ação sobre mudanças climáticas, metas de redução de emissões de gases do efeito estufa ou estudos de vulnerabilidade ${ }^{9}$.

O Estado de Minas Gerais, por exemplo, instituiu o registro voluntário de emissões e remoções de gases de efeito estufa (Decreto Estadual n $\left.n^{\circ} 45.229 / 2009\right)^{10}$ e o Fórum Mineiro de Mudanças Climáticas (Decreto $\left.n^{\circ} 44.042 / 2005\right)$. Essas são as únicas normas estaduais específicas que versam sobre instrumentos previstos na política nacional de mudanças climáticas ${ }^{11}$. Até o presente momento, não houve edição de uma lei estadual a respeito do assunto.

Se os Estados possuem, em regra, atuação tímida com relação à incorporação dos instrumentos e diretrizes da política nacional sobre mudanças climáticas, a situação é ainda mais incerta com relação aos municípios brasileiros. Além do mais, no âmbito municipal serão sentidos os principais reflexos da ausência de uma má governança multinível em matéria climática. Em visto disso, é fundamental a elaboração e execução de políticas públicas de planejamento e resposta às vulnerabilidades climáticas.

\section{PERSPECTIVAS DE ATUAÇÃo DOS ESTAdOS E MUnicíPIOS NA CONSECUÇÃO DA POLÍTICA CLIMÁTICA}

Em países que possuem grande extensão territorial e compreendem uma diversidade de ecossistemas, é fundamental que as políticas públicas sejam interiorizadas para atingir a maior abrangência possível, sem prejuízo das características próprias de cada

\footnotetext{
${ }^{8}$ As enchentes ocorridas na Europa neste ano de 2021 resultaram em quase 200 mortes e enormes perdas econômicas. Na Alemanha, houve fortes críticas ao governo em razão de sua omissão para alertar as comunidades sobre os eventos, prevenindo as perdas humanas. (G1, 2021).

${ }^{9}$ Estudo publicado no ano de 2021 pela CDP Latin America demonstrou que entre os Estados da federação, apenas 7 possuem estudos de vulnerabilidade e 5 contam com metas de redução de GEE's. O trabalho ainda menciona que a maioria dos Estados reporta a identificação de riscos, sendo os mais comuns: ondas de calor extremo, chuvas intensas e secas. (CDP, 2021)

${ }^{10}$ A implementação do Registro Público de Emissões e Remoções de Gases de Efeito Estufa do Estado de Minas Gerais foi regulamentada mediante Deliberação Normativa COPAM n 151 de 01/07/2010.

${ }^{11}$ Registra-se que o Estado de Minas Gerais possui também Plano de Energia e Mudanças Climáticas e Estudo de Vulnerabilidade Climáticas (FEAM, s.d).
} 
localidade. As mudanças climáticas são um fenômeno global, cujo enfrentamento exige ações em todos os níveis, seja para mitigação das causas da elevação da temperatura, seja para redução dos danos humanos, materiais e ecológicos. Logo, o princípio cooperativo, consagrado em âmbito internacional, transpõe-se para a esfera nacional dos Estados, de modo que em todos os níveis de atuação do poder público exista envolvimento na adoção das ações necessárias.

O Acordo de Paris prevê entre seus fundamentos o reconhecimento da “importância do engajamento de todos os níveis de governo e diferentes atores, de acordo com as respectivas legislações nacionais das Partes, no combate às mudanças do clima," (BRASIL, 2017, s.p). Outrossim, ao tratar sobre as obrigações de adaptação ${ }^{12}$, o tratado prevê:

\begin{abstract}
Art. $7^{\circ}$. (...)
2. As Partes reconhecem que a adaptação é um desafio global enfrentado por todos, com dimensões locais, subnacionais, nacionais, regionais e internacionais, e um componente fundamental da resposta global de longo prazo, para a qual também contribui, à mudança do clima, com vistas a proteger as populações, os meios de subsistência e os ecossistemas, levando em conta as necessidades urgentes e imediatas daquelas Partes países em desenvolvimento particularmente vulneráveis aos efeitos negativos da mudança do clima. (BRASIL, 2017, s.p)
\end{abstract}

Em outro momento, o Acordo de Paris faz menção expressa à atuação de entes subnacionais, ao se referir à capacitação no âmbito dos países em desenvolvimento (art. 11). A capacitação diz respeito ao fortalecimento da habilidade de adotar medidas de mitigação e adaptação eficazes, mediante educação, treinamento, conscientização pública, acesso e aplicação de tecnologias entre outras. A implementação da capacitação deve ser realizada em níveis nacionais, subnacionais e locais.

A transposição do princípio cooperativo previsto no Acordo de Paris para a ordem jurídica brasileira encontra amparo na repartição de competências federativas prevista na Constituição Federal de 1988. Em seu art. 23 é prevista a competência comum da União, dos Estados, do Distrito Federal e dos Municípios para proteção do meio ambiente e combate à poluição em qualquer de suas formas, a preservação das florestas, da fauna e da flora.

\footnotetext{
${ }^{12}$ A respeito dos objetivos de adaptação, o Acordo de Paris dispõe:

“Art. $7^{\circ}$ 1. As Partes estabelecem o objetivo global para a adaptação, que consiste em aumentar a capacidade de adaptação, fortalecer a resiliência e reduzir a vulnerabilidade à mudança do clima, com vistas a contribuir para o desenvolvimento sustentável e a assegurar uma resposta de adaptação adequada no contexto da meta de temperatura a que se refere o Artigo $2^{\circ}$. ." (BRASIL, 2017, s.p)
} 
Já o art. 24 da CF/88 define as matérias que constituem competência concorrente entre União, Estados e Distrito Federal, dentre as quais se inserem as florestas, a conservação da natureza, a defesa do solo e dos recursos naturais, a proteção do meio ambiente, do patrimônio histórico etc. No exercício da competência concorrente, compete à União definir normas gerais, que serão complementadas pela legislação dos Estados Membros, os quais poderão ainda legislar amplamente sobre as matérias relacionadas no dispositivo constitucional, desde que inexistente lei federal. Admite-se, ainda, por força do disposto no art. 30, inciso II, da Constituição Federal de 1988, que os Municípios suplementem as normas gerais da União e as normas estaduais, no exercício da competência concorrente, desde que presente o interesse local.

O papel a ser desempenhado por Estados, Distrito Federal e Municípios no exercício da competência concorrente será o de preencher as lacunas existentes na legislação federal, atentos às peculiaridades regionais e locais que demarcam seus interesses. A harmonia do arcabouço legislativo federativo, em matéria ambiental, é assegurada pelo princípio in dubio pro natura, segundo o qual, em caso de conflito será eleita a norma que estabelecer maior restrição e, por conseguinte, conceder maior efetividade ao predicado de proteção ambiental consagrado no texto constitucional (FARIAS, 1999).

Sarlet e Fensterseifer discorrem sobre o princípio do federalismo cooperativo ecológico, que decorre do sistema de repartição de competências entre os entes da Federação e dos deveres de proteção dos direitos fundamentais, notadamente, do art. 225 da Constituição Federal que estabelece a proteção ambiental pelo Estado (SARLET; FENSTERSEIFER, 2014). Nesse sentido, o dever de cooperação entre os entes para a proteção do meio ambiente em prol de gerações presentes e futuras abrange a defesa do direito fundamental ao clima estável. Observadas as particularidades regionais e locais, Estados e Municípios devem exercer sua competência legislativa e administrativa para consecução dos objetivos previstos no Acordo de Paris e na política climática nacional.

Vislumbra-se, portanto, o papel fundamental a ser exercido por Estados e Municípios para o sucesso da concretização de uma política climática nacional. À luz do federalismo cooperativo ecológico, todos os entes federativos devem exercer competências legislativas e administrativas e, por que não dizer, jurisdicionais, para a máxima efetivação dos direitos fundamentais. Reconhecendo-se que o direito ao clima estável se insere no rol de direitos fundamentais, de forma autônoma ou contido no âmbito do direito ao meio ambiente 
equilibrado, o cumprimento das obrigações assumidas no Acordo de Paris reclama uma cooperação federativa climática.

Os instrumentos da política nacional climática (Lei $\mathrm{n}^{\circ}$ 12.187/2009) apontam diversas possibilidades de atuação dos entes federativos. Do mesmo modo, a contribuição nacionalmente determinada (NDC) elaborada pelo Brasil indica as prioridades de atuação para se chegar ao objetivo de neutralidade climática. A intenção de NDC apresentada pelo país em 2015 (iNDC) estabeleceu o objetivo de redução de emissão dos gases do efeito estufa em 37\% abaixo dos níveis de 2005, em 2025 e em 43\% abaixo dos níveis de 2005, em 2030. Quanto às ações em adaptação, a NDC informa o seguinte:

\begin{abstract}
O Governo brasileiro dispensa especial atenção às populações mais pobres por intermédio de melhorias de habitação e condições de vida, constituindo um reforço em sua capacidade de resistir aos efeitos de eventos climáticos extremos. O Brasil já monitora eventos de precipitação extrema em 888 municípios e dispõe de um sistema de alerta antecipado e de planos de ação para responder a desastres naturais. Cabe notar, ainda, que o Brasil busca incrementar a sua capacidade nacional em segurança hídrica (Plano Nacional de Segurança Hídrica) e em conservação e uso sustentável da biodiversidade (Plano Estratégico Nacional de Áreas Protegidas e a regularização ambiental pelo Código Florestal, em particular das Áreas de Preservação Permanente). (BRASIL, 2015, s.p.)
\end{abstract}

Entre as metas adicionais mencionadas na iNDC, pode-se destacar: a expansão do uso de biocombustíveis, a expansão do uso de energias renováveis na matriz energética e o fortalecimento do cumprimento do Código Florestal, em âmbito federal, estadual e municipal, o desmatamento ilegal zero até 2030 e a compensação das emissões de gases de efeito de estufa provenientes da supressão legal da vegetação até 2030; a restauração florestal e ampliação do manejo sustentável de florestas nativas. Estas ações, entre outras, não podem ser atingidas sem o reconhecimento da “(...) importância do engajamento de governos locais e de seus esforços no combate à mudança do clima" (BRASIL, 2015, s.p.).

A participação de Estados, Distrito Federal e Municípios no cumprimento das obrigações internacionais enseja inúmeras possibilidades de atuação. Antes de tudo, é improtelável que os Estados omissos elaborem planos estaduais de mudanças climáticas, por simetria à política nacional, mas levando em considerações as vulnerabilidades regionais, os ecossistemas e comunidades a serem protegidos. Os municípios podem elaborar leis específicas, a depender de sua extensão territorial e população, ou incorporar os instrumentos da PNMC e das respectivas políticas estaduais aos planos diretores ou às leis ambientais 
municipais. Ademais, tendo como referências os objetivos do Acordo de Paris, propõe-se, quanto à mitigação: a obrigatoriedade do inventário de gases do efeito estufa para determinados tipos de atividades econômicas; a incorporação às matrizes de licenciamento ambiental de medidas preventivas e compensatórias de impactos climáticos; a melhoria na gestão dos resíduos sólidos; a avaliação de impactos climáticos, sobretudo em zonas costeiras. Em relação às medidas de adaptação: a incorporação aos planos municipais e estaduais de proteção e defesa civil dos riscos climáticos; o monitoramento climático e emissão de alertas de eventos extremos; o estímulo à adoção de técnicas de construção resistentes a impactos e que favoreçam o controle térmico.

\section{CONSIDERAÇÕES FINAIS}

As mudanças climáticas constituem um desafio de dimensão global. Por um lado, a ciência reconheceu fenômeno e as respostas exigidas dos países para o seu enfrentamento. De outro, é necessário compreender qual deve ser a postura ética para assegurar o equilíbrio ecológico e a manutenção da vida digna no planeta.

Os eventos climáticos extremos, relacionadas às mudanças climáticas, acarretam impactos ecológicos e humanos, impedindo o exercício de direitos individuais e coletivos. A necessidade de resguardar o equilíbrio ecológico para gerações presentes e futuras permite que se vislumbre a existência de um direito fundamental ao clima estável. Em âmbito internacional, este direito foi resguardado na Convenção-Quadro das Nações Unidas sobre Mudança Climática e seus acordos complementares, o Protocolo de Quioto e o Acordo de Paris. A Constituição Brasileira de 1988 estabelece a dignidade da pessoa humana como seu fundamento e expressamente reconhece o direito ao meio ambiente equilibrado, dando, portanto, guarida, ao direito fundamental ao clima estável.

O Brasil é signatário dos acordos internacionais sobre o clima e adotou uma política nacional que estabelece normas gerais sobre a implementação de medidas de mitigação e adaptação para o cumprimento dos compromissos assumidos pelo país junto à ONU. Contudo, para que estes objetivos sejam atingidos é necessária a cooperação entre todos os níveis da federação. Estados e Municípios possuem um papel fundamental no exercício de sua competência legislativa e administrativa em matéria ambiental para a 
realização dos instrumentos previstos na política nacional do clima, concretizando, por meio de um federalismo cooperativo ecológico, o direito fundamental ao clima estável.

\section{REFERÊNCIAS}

BRASIL. Decreto no 2.652/1998. Promulga a Convenção-Quadro das Nações Unidas sobre Mudança do Clima, assinada em Nova York, em 9 de maio de 1992. Disponível em: http://www.planalto.gov.br/ccivil_03/decreto/d2652.htm. Acesso em: 7 set. 2021.

BRASIL. Lei 12.187/2009. Institui a Política Nacional sobre Mudança do Clima - PNMC e dá outras providências. Disponível em: http://www.planalto.gov.br/ccivil_03/_ato20072010/2009/lei/112187.htm. Acesso em: 7 set. 2021.

BRASIL. Decreto n⿳ 9.073/2017. Promulga o Acordo de Paris sob a Convenção-Quadro das Nações Unidas sobre Mudança do Clima, celebrado em Paris, em 12 de dezembro de 2015, e firmado em Nova Iorque, em 22 de abril de 2016. Disponível em: http://www.planalto.gov.br/ccivil_03/_ato2015-2018/2017/decreto/d9073.htm. Acesso em: 7 set. 2021.

BRASIL. Pretendida contribuição nacionalmente determinada para consecução do objetivo da Convenção-Quadro das Nações Unidas sobre Mudança do Clima (2015). Disponível em:http://www.itamaraty.gov.br/images/ed_desenvsust/BRASIL-iNDCportugues.pdf.Acesso em 24 abr. 2021.

BRASIL. Paris Agreement. Brazil's Nationally Determined Contribution (2020). Disponível em: https://www4.unfccc.int/sites/ndcstaging/PublishedDocuments/Brazil\%20First/Brazil\%20First\%20NDC\%20(Updated\%20submission).pdf. Acesso em 24 abr. 2021.

CDP LATIN AMERICA. Como os governos estaduais brasileiros enfrentam a mudança do clima? Resumo das respostas dos estados brasileiros ao questionário de Estados e Regiões de 2020 do CDP. Disponível em: https://6fefcbb86e61af1b2fc4c70d8ead6ced550b4d987d7c03fcdd1d.ssl.cf3.rackcdn.com/cms/reports/documents/000/005/8 45/original/CDP-relatorio-governoseclima-FINAL_.pdf?1628892687. Acesso em: 6 set. 2021.

CHRISTOFOLI, Bruno de Andrade. Direito das mudanças climáticas: sistema de comércio de emissões no Brasil. Rio de Janeiro: Lumen Juris, 2017.

FARIAS, Paulo José Leite. Competência federativa e proteção ambiental. Porto Alegre: Sergio Antônio Fabris, 1999.

FUNDAÇÃO ESTADUAL DO MEIO AMBIENTE (FEAM). Publicações. Informações disponíveis $\quad \mathrm{em}$ : http://www.feam.br/-sustentabilidade-energia-e-mudancasclimaticas/publicacoes. Acesso em: 6 set. 2021. 
Sobe para 196 o $\mathrm{n}^{\mathbf{0}}$ de mortos pelas chuvas na Europa. G1, 19 jul. 2021. Disponível em: https://g1.globo.com/mundo/noticia/2021/07/19/chuvas-na-europa-sobe-o-numero-de-mortosna-alemanha-e-na-belgica.ghtml. Acesso em: 6 set. 2021.

Intergovernmental Panel on Climate Change (IPCC). Climate Change 2014: Synthesis Report. Gênova, 2014. Disponível em: https://www.ipcc.ch/report/ar5/syr/. Acesso em 8 ag. 2021.

Intergovernmental Panel on Climate Change (IPCC). Summary for Policymakers. In: Climate Change 2021: the Physical Science Basis. Contribution of Working Group I to the Sixth Assessment Report of the Intergovernmental Panel on Climate Change. Cambridge University Press, 2021. Disponível em: https://www.ipcc.ch/report/ar6/wg1/. Acesso em: 7 set. 2021.

Intergovernmental Panel on Climate Change (IPCC). The Intergovernmental Panel on Climate Change. Disponível em: https://www.ipcc.ch/. Acesso em: 3 set. 2021.

JONAS, Hans. O princípio responsabilidade: Ensaio de uma ética para a civilização tecnológica. Rio de Janeiro: Contraponto: Ed. PUC-RIO, 2006.

SARLET, Ingo Wolfgang; FENSTERSEIFER, Tiago. Direito constitucional ecológico. São Paulo: Thomson Reuters, 2019.

SARLET, Ingo Wolfgang; FENSTERSEIFER, Tiago. Notas acerca do Princípio do Federalismo Cooperativo Ecológico e do Correlato Princípio (e Dever) de Subsidiariedade. In: CAMPELLO, Lívia Gaigher Bósio; SOUZA, Maria Cláudia da Silva; PADILHA, Norma Sueli (Orgs.). Direito Ambiental no Século XXI: Efetividade e Desafios, volume III. Belo Horizonte: Arraes Editores, 2014. p. 13-27.

Tiago Fensterseifer participa da ADPF 708 sobre o Fundo do Clima e a proteção ambiental no STF. [S.I.: s.n.], 25 set. 2020. 1 vídeo (8 min). Publicado pelo canal GEN Jurídico. Youtube, 25 set. 2020. Disponível em: https://www.youtube.com/watch?v=XBHnP1rhCYM. Acesso em: 5 set. 2021.

WEDY, Gabriel. Desenvolvimento sustentável na era das mudanças climáticas: um direito fundamental. São Paulo: Saraiva Educação, 2018. 